【Review】

\title{
Anti-HIV Mechanism of Sulfated Poly and Oligosaccharides
}

\author{
Takashi Yoshida\# \\ Department of Bio and Environmental Chemistry, Kitami Institute of Technology, 165 Koen-cho, \\ Kitami 090-8507, Hokkaido, Japan
}

\begin{abstract}
This review focuses on the previous and recent results as well as related literatures regarding the anti-HIV mechanism of sulfated alkyl poly- and oligosaccharides.

To clarify the anti-HIV mechanism of sulfated polysaccharides, curdlan sulfate was mainly used because of having potent anti-HIV activity and low cytotoxicity. Curdlan sulfate was prepared by sulfation of a natural occurring polysaccharide curdlan bearing linear $(1 \rightarrow 3)-\beta$-D-glucopyranosidic structure. Nuclear magnetic resonance (NMR) analysis of the mixture of curdlan sulfate and an oligopeptide from the C-terminus of HIV envelope (surface) glycoprotein gp120 (HIV gp120) suggested that the anti-HIV activity of curdlan sulfate depended on electrostatic interactions between negatively charged sulfate groups in sulfated polysaccharides and positively charged amino acids in HIV gp120. The mechanism was assumed to be similar to the electrostatic interaction between a natural blood anticoagulant sulfated polysaccharide heparin and a protease inhibitor antithrombin III. In addition, the anti-HIV mechanism of curdlan sulfate was quantitatively investigated using surface plasmon resonance (SPR) and dynamic light scattering (DLS) measured with oligopeptides from three regions in HIV gp120, V3 loop, C-terminus, and CD4 binding domain. These studies revealed the interaction between oligopeptides of the V3 loop and C-terminus bearing positively charged amino acid accumulated regions in each sequence. These results indicated that the anti-HIV activity of sulfated polysaccharides involves electrostatic interactions.

It was reported that a long-chain alkyl group in sulfated alkyl oligosaccharides plays a key role in the enhancement of anti-HIV activity. The interaction between sulfated alkyl poly- and oligosaccharides and liposomes as a model of HIV was also discussed by SPR and DLS measurements, suggesting that the longchain alkyl group penetrated into the lipid bilayer of HIV, and then sulfated poly- and oligosaccharide portions electrostatically interacted with HIV gp120 to produce potent anti-HIV activity.
\end{abstract}

(Received 23 August, 2020; Accepted 11 October, 2020)

\section{Introduction}

Polysaccharides are the most abundant natural resource on earth, and humans have used them for food, fiber, construction material, and so on. Additionally, polysaccharides have specific biological activities against cancers, blood coagulation, and viruses $[1,2]$. Thus, a better understanding of structure-activity relationships and underlying biological mechanisms involving polysaccharides could lead to the development of new biological materials.

In general, naturally occurring polysaccharides have complex structures and it is difficult to investigate structure-biological activity relationships and biological mechanisms. Ring - opening polymerization of anhydro sugar monomers is a superior method to obtain stereoregular polysaccharides with defined structures and high molecular weights [3, 4]. The molecular weight distribution $\left(\overline{\mathrm{M}}_{\mathrm{w}} / \overline{\mathrm{M}}_{\mathrm{n}}\right)$ of the resulting polysaccharides is also narrow. Therefore, we synthesized many stereoregular polysaccharides and evaluated the relationship between the structure of polysaccharides and biological activity by using both synthetic and naturally occurring polysaccharides [5]. This review

\# corresponding author: Takashi Yoshida (E-mail: yoshida@chem.kitami-it.ac.jp) 
deals with the anti-HIV mechanism of sulfated polyand oligosaccharides based on the precise poly- and oligosaccharide syntheses.

\section{Synthesis of sulfated polysaccharides with potent antiviral activity}

\subsection{Ring-opening polymerization of anhydro sugar monomers}

For the synthesis of stereoregular polysaccharides, it was reported for the first time in 1966 that $(1 \rightarrow 6)-\alpha$-D-glucopyranan, synthetic dextran, was synthesized by ring-opening polymerization of a benzylated 1, 6-anhydro glucose monomer, 1, 6anhydro-2, 3, 4-tri- $O$-benzyl- $\beta$-D-glucopyranose (LGTBE), followed by debenzylation to recover hydroxyl groups as exhibited in Scheme 1 [6].

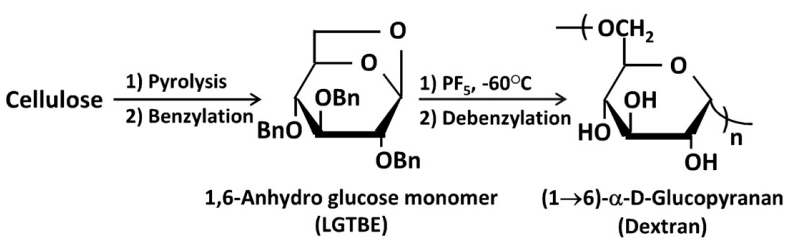

Scheme 1 The first synthesis of stereoregular polysaccharides by Schuerch. The ringopening polymerization of anhydro sugar monomer LGTBE gave $(1 \rightarrow 6)-\alpha$-D glucopyranan bearing high molecular weights in good yields.

After this report on the ring-opening polymerization, many anhydro sugar monomers including 1, 4-anhydro pentose monomers were synthesized and polymerized to produce stereoregular polysaccharides and the polymerization

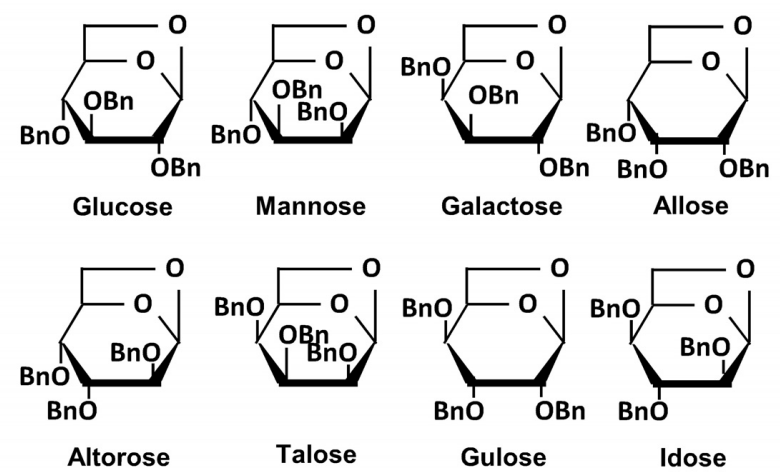

Fig. 1 Eight 1, 6-anhydro hexose monomers.

Six 1, 6-anhydro hexose monomers among eight hexoses were synthesized and polymerized by ring-opening polymerization into the corresponding stereoregular polysaccharides.

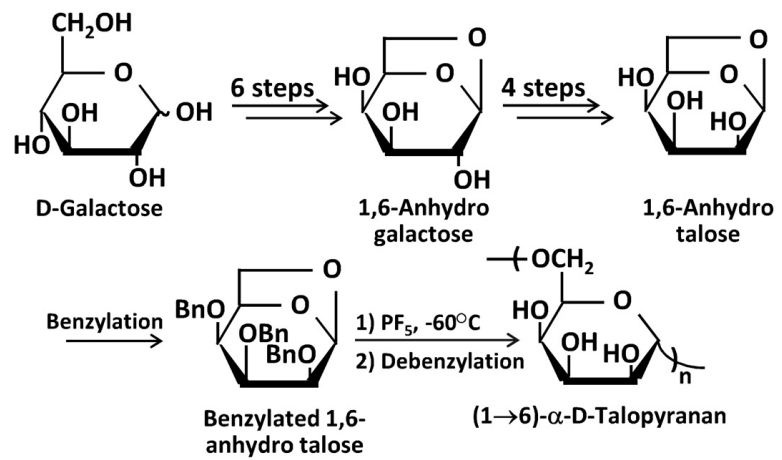

Scheme 2 Synthesis and ring-opening polymerization of 1,6 -anhydro-2, 3, 4- tri-O-benzyl- $\beta$-Dtalopyranose into $(1 \rightarrow 6)-\alpha$-D-talopyranan

mechanism was also reported [7-11].

Thus, six 1, 6-anhydro hexose monomers in eight hexoses have been polymerized or copolymerized to give the corresponding stereoregular $(1 \rightarrow 6)$ - $\alpha$-Dhexopyranans as shown in Fig. 1. Scheme 2 exhibits the synthesis and polymerization of 1, 6-anhydro-2, 3, 4 -tri- $O$-benzyl- $\beta$-D-talopyranose (benzylated 1, 6anhydro talose monomer), which is the sixth monomer for polymerization. The ring-opening polymerization of the benzylated 1, 6-anhydro talose monomer using $\mathrm{PF}_{5}$ as a catalyst produced the corresponding stereoregular benzylated $(1 \rightarrow 6)-\alpha$-D-talopyranan [12]. The molecular weights were high $\left(\overline{\mathrm{M}}_{\mathrm{n}}=9.5 \times 10^{3}-19.6\right.$ $\times 10^{3}$ ). After deprotection of benzyl groups to recover hydroxyl groups, $(1 \rightarrow 6)$ - $\alpha$-D-talopyranan bearing $\overline{\mathrm{M}}_{\mathrm{n}}=$ $10.5 \times 10^{3}$ was obtained. The two remaining hexoses, Dgulose and D-idose monomers will be also synthesized and then ring-opening polymerization can be performed.

Although starting anhydro sugar monomers are generally synthesized by vacuum pyrolysis of monosaccharides or cellulose and maltose in approximately $10 \%$ yield, or by a stepwise preparation from monosaccharides, ring-opening polymerization proceeded for a short time in good yields [3-5]. In addition, 1, 6-anhydro glucopyranose is found to be present in wood tar in a high concentration and the isolated 1, 6-anhydro glucopyranose was used as a starting monomer [13].

\subsection{Sulfated polysaccharides with blood anticoagulant activity}

Polysaccharides were sulfated with several commercially available sulfating reagents such as $\mathrm{SO}_{3-}$ pyridine in DMSO, $\mathrm{SO}_{3}-\mathrm{DMF}$ in $\mathrm{DMF}, \mathrm{SO}_{3-}$ trimethylamine in DMF, or chlorosulfonic acid in pyridine to produce sulfated polysaccharides. Pyperidine- $N$-sulfonic acid (PSA) was a superior 
sulfating reagent [14]. The procedure for sulfation is simple [5]. First add PSA to a clear solution of dry curdlan in anhydrous DMSO and stir for $2 \mathrm{~h}$ at $85^{\circ} \mathrm{C}$. After cooling, the mixture is neutralized with $5 \%$ $\mathrm{NaOH}$ aqueous solution and subsequently dialyzed against deionized water for $24 \mathrm{~h}$. The dialysate is concentrated and freeze-dried to produce curdlan sulfate as a white precipitate in good yields. The degree of sulfation and molecular weights depend on the amount of PSA and solvent, temperature, and time.

Sulfated polysaccharides have a characteristic blood anticoagulant activity (AA). A specific example is heparin, which is a naturally occurring sulfated polysaccharide with potent blood anticoagulant activity and used for medical purposes [15, 16]. Heparin is biosynthesized in liver, lung, intestine, and other tissues as a glycoprotein on cells and the pentasaccharide moiety in the polysaccharide chains branching off from the core protein is a key sequence for blood anticoagulant activity. The blood anticoagulant mechanism of heparin was reported by Lindahl and demonstrated that the negatively charged pentasaccharide residue (Fig. 2) electrostatically interacted with the positively charged lysine site of a protease inhibitor antithrombin III to form a heparin-antithrombin III complex that inhibits the activity of the blood coagulant factor thrombin to prevent blood coagulation $[17,18]$.

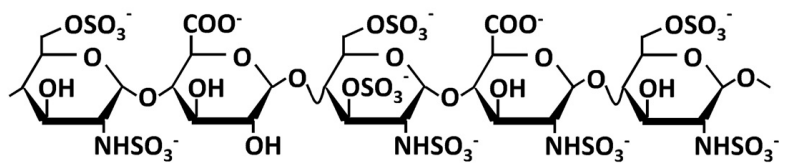

Fig. 2 Structure of heparin pentasaccharides residue. Heparin is electrostatically interacted with antithrombin III, a protease inhibitor, to form heparin-antithrombin III complex that inhibits the activity of thrombin.

Stereoregular synthetic dextran sulfates obtained by ring-opening polymerization and subsequent sulfation (Scheme 3) also exhibit blood anticoagulant activity, 49-59 unit/mg, which activity was higher than that $(20.6 \mathrm{unit} / \mathrm{mg}$ ) of standard dextran sulfate (Meito Sangyo NC-1032) [19, 20]. The higher activity may be ascribed to the higher molecular weights of synthetic dextran sulfates. In the next section, the structure and anti-HIV activity relationship of sulfated polysaccharides is described.

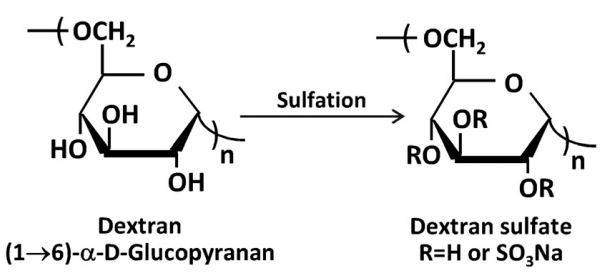

Scheme 3 Synthesis of stereoregular dextran sulfate by sulfation of synthetic dextran.

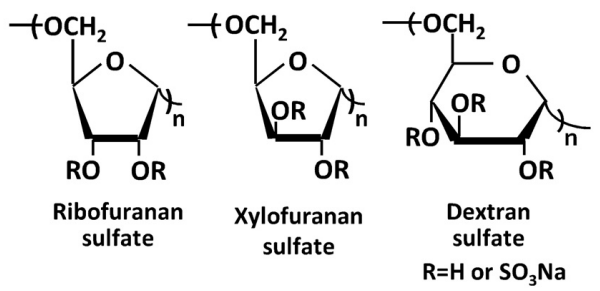

Fig. 3 Structure of ribofuranan, xylofuranan, and dextran sulfates obtained by ring-opening polymerization of the corresponding anhydro sugar monomers, respectively, and then sulfation. These synthetic polysaccharides were found to have potent anti-HIV activity.

\subsection{Anti-HIV activity of sulfated polysaccharides}

For the antiviral activity of sulfated polysaccharides, lower blood anticoagulant activity is preferable because higher anticoagulant activity is a side effect of antiviral agents. Fig. 3 shows the structure of sulfated synthetic polysaccharides, ribofuranan, xylofuranan, and dextran sulfates obtained by ring-opening polymerization of the corresponding 1, 4-anhydro ribose, xylose, and 1, 6anhydro glucose monomers, respectively. In 1987, it was found for the first time that sulfated synthetic polysaccharides completely inhibited HIV infection $\left(\mathrm{EC}_{100}\right)$ in concentrations as high as $\mathrm{EC}_{100}<3.3 \mu \mathrm{g} / \mathrm{mL}$ [21]. These sulfated synthetic polysaccharides had high anti-HIV activity, however, blood anticoagulant activity was relatively higher than that of standard dextran sulfate $(\mathrm{AA}=22.7 \mathrm{unit} / \mathrm{mg})$. The sulfated synthetic polysaccharides efficiently inhibited the reverse transcriptase activity of avian myelobiastosis virus and HIV. For cytotoxicity, xylofuranan and ribofuranan sulfates exhibited no effect on the MT-4 cell growth at this concentration, although dextran sulfate showed $20-30 \%$ growth inhibition of HIVuninfected MT-4 cells at $1000 \mu \mathrm{g} / \mathrm{mL}$. The present strategy for the chemical modification of synthetic and naturally occurring polysaccharides could be significant for the elucidation of the antiviral mechanism of sulfated polysaccharides and for the development of new antiretroviral biomaterials. The completely inhibited concentration $\left(\mathrm{EC}_{100}\right)$ is equal to 
below $1.0 \mu \mathrm{g} / \mathrm{mL}$ for the $50 \%$ effective concentration $\left(\mathrm{EC}_{50}\right)$. High anti-HIV activity reflects small $\mathrm{EC}_{50}$ values and low cytotoxicity with large $\mathrm{CC}_{50}$ values. In addition, large AA values indicate high blood anticoagulant activity.

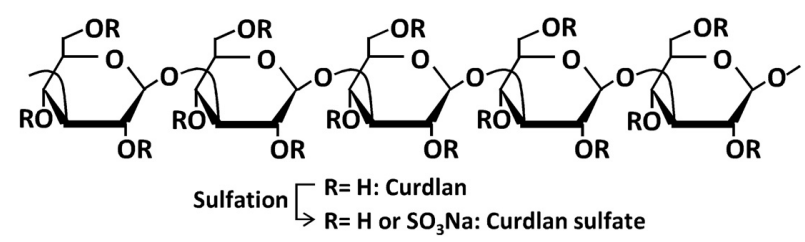

Fig. 4 Synthesis of curdlan sulfate by sulfation of naturally occurring curdlan. Curdlan sulfate had high anti-HIV activity $\left(\mathrm{EC}_{100}=3.3 \mu \mathrm{g} / \mathrm{mL}\right)$, low cytotoxicity $\left(\mathrm{CC}_{50}>1000 \mu \mathrm{g} / \mathrm{mL}\right)$, and low anti-HIV activity (AA=10 unit/mg). (Degree of sulfation: $\left.1.2-1.6(\max .3 .0), \bar{M}_{\mathrm{n}}=20000-80000\right)$.

Fig. 4 shows the structure of curdlan sulfate prepared by sulfation of naturally occurring curdlan bearing a linear $(1 \rightarrow 3)-\beta$-D-glucopyranosidic structure produced by Alcaligenes faecalis var. myxogenes 10C3 strain [22]. Curdlan sulfate was found to have potent anti-HIV activity in concentrations as high as $\mathrm{EC}_{100}<$ $3.3 \mu \mathrm{g} / \mathrm{mL}\left(=\mathrm{EC}_{50}<1.0 \mu \mathrm{g} / \mathrm{mL}\right)$ with low cytotoxicity $\mathrm{CC}_{50}>1000 \mu \mathrm{g} / \mathrm{mL}$ [23]. Curdlan sulfate had low blood anticoagulant activity less than $\mathrm{AA}=10$ unit/mg compared with that of standard dextran sulfate $(\mathrm{AA}=$ 22.7 unit/mg).

The blood anticoagulant activity of heparin and sulfated polysaccharides was discussed in section 2-2, suggesting the electrostatic activation of a protease inhibiter antithrombin III to express the activity. For sulfated synthetic polysaccharides, sulfated ribo and xylofuranans exhibited higher blood anticoagulant activity than that of curdlan sulfate, compared with that of standard dextran sulfate $(22.7 \mathrm{unit} / \mathrm{mg})$ as described in this section. The anticoagulant activity was considered from the view point of the structure of polysaccharides. The polysaccharide backbone of furanan type polysaccharides is more flexible than that of the pyranan type polysaccharides, which flexibility could be originated from the high blood anticoagulant activity of furanan type polysaccharides. Namely, the flexible structure might be favorable for interacting blood anticoagulant factors, for example, antithrombin III. Secondly, a regular structure of polysaccharides might be one of the reasons for the high activity, because sulfated random copolysaccharides consisting of $(1 \rightarrow 5)-\alpha-D$ xylofuranose and -ribofuranose monomeric units had a lower blood anticoagulant activity at $\mathrm{AA}=23.7$ unit/ mg than that of each stereoregular $(1 \rightarrow 5)-\alpha$-Dxylofuranan and $(1 \rightarrow 5)-\alpha$-D-ribofuranan, $\quad \mathrm{AA}=$ $69.1 \mathrm{unit} / \mathrm{mg}$ and $56.0 \mathrm{unit} / \mathrm{mg}$, respectively [19]. Thirdly, as described below, the branched structure also accelerates blood anticoagulant activity probably because of increasing the chance of electrostatic interaction between sulfated branched sugars and blood anticoagulant factors. Therefore, curdlan sulfate exhibited lower blood anticoagulant activity because curdlan has a rigid and linear $(1 \rightarrow 3)-\beta$-pyranosidic structure like cellulose bearing $\beta-(1 \rightarrow 4)$ glucopyranosidic structure.

Lentinan, a naturally occurring potent immunomodulatory and antitumor polysaccharide, has $(1 \rightarrow 3)-\beta$-D-glucopyranosidic structure bearing 1 , 6 glucopyranose branches. After sulfation, lentinan sulfate completely prevented the infection of HIV at the concentration below $10 \mu \mathrm{g} / \mathrm{mL}$ and did not inhibit the growth of MT- 4 cells at the concentration more than $500 \mu \mathrm{g} / \mathrm{mL}$ [24]. The anticoagulant activity was determined as $23 \mathrm{unit} / \mathrm{mg}$, which is relatively higher than that of curdlan sulfate, $10 \mathrm{unit} / \mathrm{mg}$. As described above, curdlan has linear $(1 \rightarrow 3)-\beta$-pyranosidic structure and lentinan branched $(1 \rightarrow 3)-\beta$-pyranosidic structure, suggesting that the branched structure contributed to the anticoagulant activities. On the other hand, lentinan is a medicine for cancer and the price is high. Therefore, curdlan sulfate was a superior candidate for a HIV drug due to high antiHIV activity, low cytotoxicity, and low blood anticoagulant activity. The price is low. A phase I/II study of curdlan sulfate revealed that the level of CD4 positive helper $\mathrm{T}$ lymphocytes increased upon intravenous injection of curdlan sulfate in patients infected with HIV [25, 26]. Namely, curdlan sulfate was effective for the treatment of HIV because the number of $\mathrm{CD} 4$ positive helper $\mathrm{T}$ lymphocytes decrease by HIV infection.

To investigate the relationship between the proportion of branches and anti-HIV activity, sulfated branched polysaccharides were synthesized by ringopening polymerization of a disaccharide monomer, benzylated 1, 6-anhydro lactose (LSHBE), which was stepwise synthesized from D-lactose (Scheme 4) [27]. Sulfated $(1 \rightarrow 6)-\alpha$-D-lactopyranan bearing galactose branches in every monomeric unit of the $(1 \rightarrow 6)-\alpha$-Dglucopyranosidic main chain had moderate anti-HIV activity with $\mathrm{EC}_{50}=5.9$ and $1.3 \mu \mathrm{g} / \mathrm{mL}$ (standard curdlan sulfate, $\mathrm{EC}_{50}=0.1 \mu \mathrm{g} / \mathrm{mL}$ ). The anti-HIV activity increased with decreasing the proportion of 


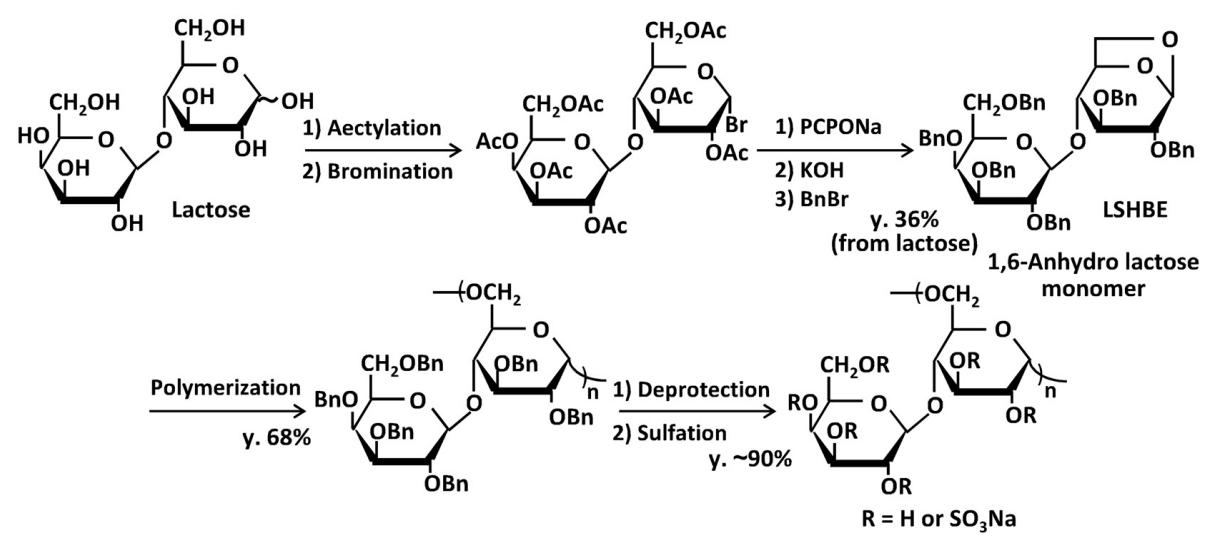

Scheme 4 Synthesis and ring-opening polymerization of benzylated 1, 6-anhydro lactose monomer into sulfated branched lactopyranan.

lactose units. When the proportion was $15 \mathrm{~mol} \%$, the anti-HIV activity increased to the highest value, $\mathrm{EC}_{50}=$ $0.3 \mu \mathrm{g} / \mathrm{mL}$. The blood anticoagulant activity was relatively low (AA=18 or $13 \mathrm{unit} / \mathrm{mg})$ for sulfated $(1 \rightarrow$ $6)-\alpha$-D-lactopyranan compared with that of standard dextran sulfate (22.7 unit/mg). Blood anticoagulant activity increased to $\mathrm{AA}=54 \mathrm{unit} / \mathrm{mg}$ when the lactose unit was $15 \mathrm{~mol} \%$. Similar anti-HIV effects of sulfated glycodendrimers were recently obtained [28]. Three new spherical sulfated cellobiose-polylysine dendrimers bearing the first, second, and third generations were prepared, and the $\mathrm{EC}_{50}$ values were 3.7, 0.6 , and $1.5 \mu \mathrm{g} / \mathrm{mL}$, respectively. The secondgeneration dendrimer was the most active, suggesting that a moderate distance between terminal sulfated cellobiose units in the second generation dendrimer favored high anti-HIV activity for the effective electrostatic interactions due to the cluster effect of the sulfated cellobiose unit revealed by SPR measurements. These biological results indicate that the distance between sulfated sugar units plays a significant role in anti-HIV and blood anticoagulant activities.

\subsection{Anti-dengue fever and anti-Influenza virus activities}

Curdlan sulfate was also found to inhibit the infection of dengue fever virus. An electron microscopic feature suggests that curdlan sulfate interacts directly with dengue fever virus envelope proteins and causes changes to the viral surface [29]. Curdlan sulfate effectively inhibits the replication of dengue fever virus in a minimum concentration at $\mathrm{EC}_{50}=0.1 \mu \mathrm{g} / \mathrm{mL}$.

Sulfated galactomannans were synthesized and had potent anti-HIV activity $\left(\mathrm{EC}_{50}=0.04-0.8 \mu \mathrm{g} / \mathrm{mL}\right)$ in concentrations as high as that of curdlan sulfate $\left(\mathrm{EC}_{50}\right.$
$=0.1 \mu \mathrm{g} / \mathrm{mL}$ ) and moderate to high anticoagulant activity (AA=13.4-36.6 unit/mg) compared with dextran sulfates ( $\mathrm{AA}=22.7 \mathrm{unit} / \mathrm{mg}$ and $10.0 \mathrm{unit} / \mathrm{mg}$ ). Sulfated galactomannan inhibited the infection of dengue fever virus activity in LCC-MK2 cells $\left(\mathrm{EC}_{50}=\right.$ $0.2-1.1 \mu \mathrm{g} / \mathrm{mL}$ ) that values were almost the same as those of curdlan sulfates $\left(\mathrm{EC}_{50}=0.1 \mu \mathrm{g} / \mathrm{mL}\right)$ [30]. Cytotoxicity in MT-4 and LCC-MK2 cells was low. SPR measurements revealed strong interaction with poly-L-lysine, which is composed of only positively charged amino acid, lysine, and is used as a model of a viral envelope (surface) protein HIV gp120. These results suggest that the anti-dengue fever virus and anti-HIV activities might originate from the electrostatic interaction between the negatively charged sulfate groups and positively charged amino acids of virus envelope proteins.

To develop a biomaterial with influenza A virusadsorptive functionality, an alkyl group, didodecyldimethyl ammonium bromide, was introduced into curdlan sulfate (1 didodecyldimethyl group/12 glucose residues) by an ionic bond between positively charged ammonium and negatively charged sulfate groups [31]. The alkyl curdlan sulfatecoated membrane filter ( $\phi 13 \mathrm{~mm}$; pore size, $1 \mu \mathrm{m})$ was prepared and found to have specific adsorptive functionality for influenza A virus in vitro. The diameter of the influenza A virus is approximately $100 \mathrm{~nm}$. Three stacked membrane filters dramatically decreased haemagglutination from $1 / 4$ to $1 / 32$. The alkyl curdlan sulfate-coated membrane filter did not work effectively in the removal of influenza B viruses. According to the influenza research database [32], the proportion of basic amino acids in the envelope protein, haemagglutinin, on influenza B viruses is less than that of influenza A viruses. Therefore, the 
electrostatic interaction of sulfated polysaccharides with envelope glycoproteins on viruses is an important role in the potent antiviral activity.

Further research on the mechanism suggests that the oligosaccharide-binding site for pulmonary surfactant protein $\mathrm{D}$ to the globular domain of haemagglutinin is critical in mediating the inhibition of viral haemagglutination activity and infectivity [33]. These results indicate that sulfated polysaccharides should effectively inhibit infections from envelop viruses. The antiviral mechanism against influenza $\mathrm{A}$ and dengue fever viruses should be similar to the antiHIV mechanism described in the next section.

\subsection{Anti-HIV mechanism of sulfated polysaccharides}

The antiviral mechanism of sulfated polysaccharides is expected to involve the electrostatic interaction between sulfated polysaccharides and surface glycoproteins on viruses. Given the anticoagulant interaction between heparin and antithrombin III as described in section 2-2, the anti-HIV activity of sulfated polysaccharides may be involve electrostatic interactions that inhibit the HIV infection [34]. Fig. 5 shows the proposed electrostatic interaction of curdlan sulfate with HIV gp120 at the Cterminus, which is one of the positively charged lysine and arginine accumulated portions. In the C-terminus, there are seven positively charged amino acids, lysine and arginine, in a sequence of 20 amino acids. The negatively charged sulfate groups of curdlan sulfate might electrostatically interact with the positively charged amino acids to prevent binding of HIV to CD4 positive helper $\mathrm{T}$ lymphocytes.

To reveal this mechanism for the anti-HIV activity, the inhibitory effects of curdlan sulfate were analyzed against HIV-1 infected CD4 positive supT-1 lymphoma cells and peripheral blood lymphocytes. The results revealed that curdlan sulfate was bound to the V3 loop of HIV gp120 and that T-cell (T) tropic HIV was 10-fold more sensitive to neutralization by curdlan sulfate than macrophage (M) tropic HIV, because surface glycoproteins on macrophages had a relatively less positively-charged amino acid composition [35, 36]. The effect of curdlan sulfate on the binding of HIV neutralizing antibodies to HIV gp 120 demonstrated that both continuous epitopes on the V3 loop and discontinuous CD4 binding site were targets for curdlan sulfate. These results suggest that curdlan sulfate interferes with the membrane fusion process during HIV-1 infection. In addition, studies that examined the effect of curdlan sulfate on the binding of neutralizing antibodies to monomeric and oligomeric HIV gp120 mutants of the T and M tropic HIV-1 clones revealed that the amino acid composition of the V3 loop appears to determine the extent of the interaction between curdlan sulfate and the V2 and CD4 binding regions. The automated

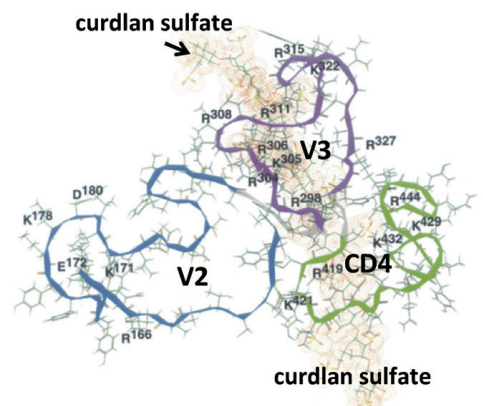

Fig. 6 Proposed electrostatic interaction of curdlan sulfate with V2, V3, and CD4 domains of HIV gp120. The V3 domain represents the most probable site for the interaction with curdlan sulfate because of having six positively charged amino acid residues located near. The $\mathrm{V} 2$ and CD4 domains have less positively amino acid residues compared with the V3 loop. (Jagodzinski et al., Virology, 225, 217 (1996))

C-terminus of HIV surface glycoprotein gp120

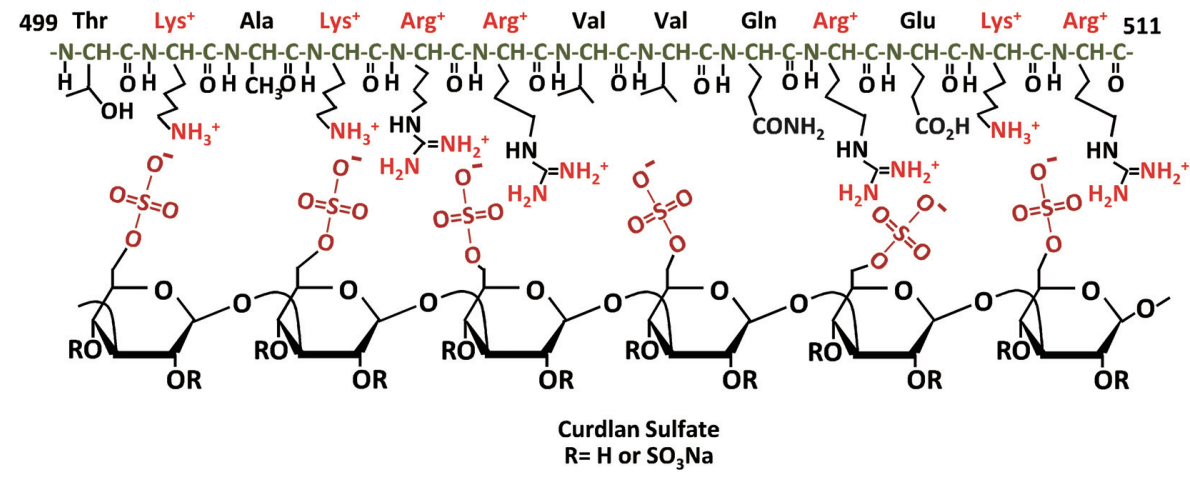

Fig. 5 Proposed electrostatic interaction of curdlan sulfate with HIV surface glycoprotein gp120. (Uryu et al., Biochem. Pharmacol,. 43, 2385 (1992)) 
A

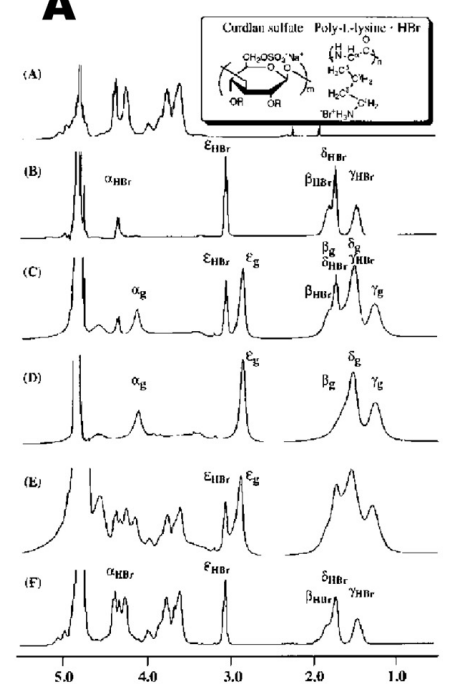

B

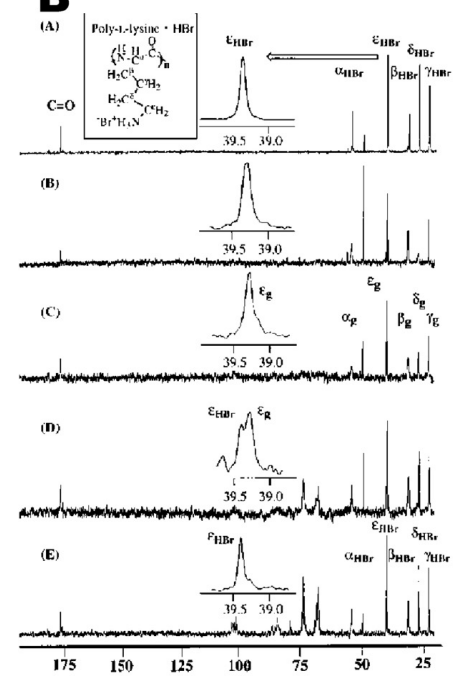

Fig. $7400 \mathrm{MHz}{ }^{1} \mathrm{H}$ and $100 \mathrm{MHz}{ }^{13} \mathrm{C}$ NMR spectra of curdlan sulfate (CS), poly-Llysine $\mathrm{HBr}(\mathrm{PL})$, and polyion complexes (PIC) between CS and PL at different molar ratios (CS/PL).

Fig. 7A: (A) curdlan sulfate; (B) poly-L-lysine-HBr; (C) PIC at a molar ratio of 0.5; (D) PIC at a molar ratio of 0.8; (E) PIC at a molar ratio of 1.0; (F) PIC at a molar ratio of 2.0. The concentration of $\mathrm{PL}$ is $2.8 \%(\mathrm{w} / \mathrm{v})$.

Fig. 7B: (A) poly-L-lysine-HBr; (B) PIC at a molar ratio of 0.5; (C) PIC at a molar ratio of 0.8; (D) PIC at a molar ratio of 1.0; (E) PIC at a molar ratio of 2.0. The concentration of PL is 2.8\% (w/v). (Jeon et al., Macromolecules, 30, 1997 (1997))

fitting procedure by the Chem X software reveals that the V3 domain represents the most probable site for the interaction with curdlan sulfate, as illustrated in Fig. 6 [36].

The anti-HIV mechanism was also analyzed by NMR measurements of a mixture of curdlan sulfate and poly-L-lysine as a model of HIV gp120 [37]. In the ${ }^{1} \mathrm{H}$ NMR measurement of curdlan sulfate and poly-Llysine mixture (Fig. 7A), it was found that gel-like complexes were formed.

The gel formation would be affected by changing several reaction conditions such as the ratio, concentration, molecular weight of curdlan sulfate, $\mathrm{pH}$, and temperature. For a molar ratio (CS/PL) of 0.5 in spectrum 7AC, signals due to poly-L-lysine appeared as two peaks at 3.03 and $2.84 \mathrm{ppm}$ due to a side chain $\varepsilon$ proton in poly-L-lysine and a new species formed by interactions between curdlan sulfate and poly-L-lysine. It is assumed that sulfate anions in curdlan sulfate interacted with ammonium cations in poly-L-lysine to form an insoluble gel-like complex. In the ${ }^{13} \mathrm{C}$ NMR spectra as shown in Fig. 7B, signals due to curdlan sulfate disappeared as background for a molar ratio smaller than 0.8. Regarding the absorptions of poly-Llysine, $\alpha$ and $\beta$ carbon signals of the poly-L-lysine side chain were broadened by the formation of the complex. Disappearance of the absorption due to curdlan sulfate and broadening of $\alpha$ and $\beta$ carbon signals clearly demonstrate a lack of local motion of the polymer backbone due to the formation of high molecular weight polyion complexes. All absorptions due to $\gamma$ and $\varepsilon$ carbons of poly-L-lysine were individually split into two peaks due to the coexistence of unreacted free poly-L-lysine and the gel-like complex. The NMR measurements indicated that curdlan sulfate has a strong interaction with poly-L-lysine consisted in the positively charged amino group known to act as a cation in biological systems. It is presumed that the anti-HIV activity of curdlan sulfate originates from its ionic interactions with a viral envelope glycoprotein.

To further elucidate the anti-HIV mechanism of curdlan sulfate, an oligopeptide sequence of a dimer (D 518) from nos. 506 to 518 at the C-terminus of HIV gp120 was synthesized and the interaction was measured by NMR [38]. As shown in Fig. 5, the Cterminus sequence has several positively charged lysine and arginine residues located nearby [34]. In the ${ }^{1} \mathrm{H}$ and ${ }^{13} \mathrm{C}$ NMR spectra as shown in Fig. 8, signals due to positively charged lysine $(\mathrm{K})$ and arginine $(\mathrm{R})$ were moved to higher and lower magnetic fields and broadly compared with those before addition of curdlan sulfate, based on assumptions that ionic interactions occurred between negatively charged 

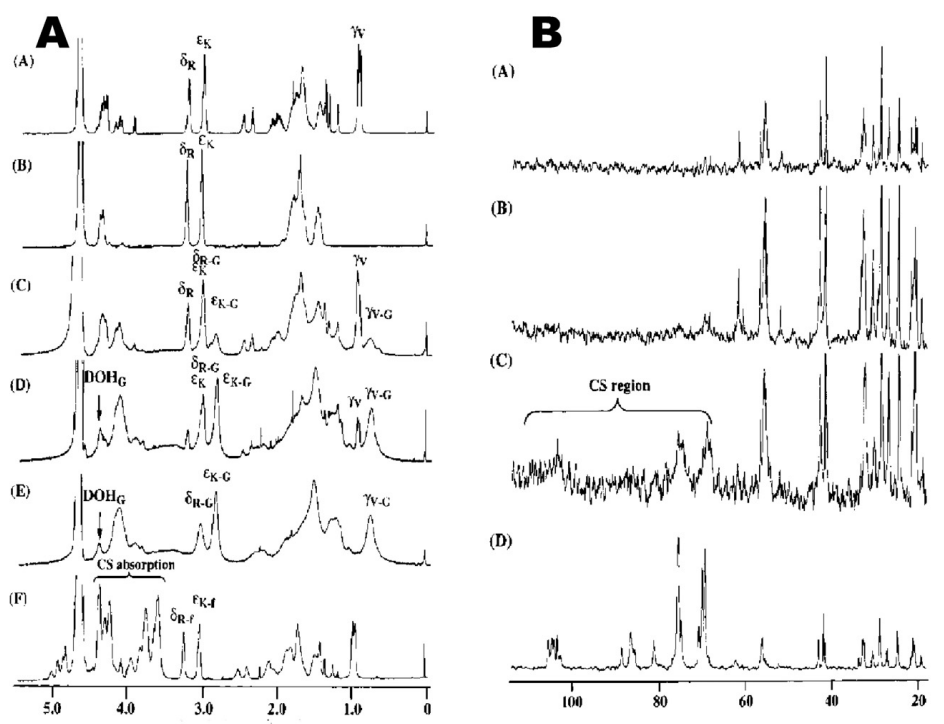

Fig. $8500 \mathrm{MHz}{ }^{1} \mathrm{H}$ and $125 \mathrm{MHz}{ }^{13} \mathrm{CNMR}$ spectra of D 518 and mixtures of curdlan sulfate (CS) with D 518 in different molar ratios.

Fig. 8A: D 518 (A) and a mixture of polylysine (PL) with polyarginine (PA) in the molar ratio of PL to PA of 4:3 (B) and in the molar ratio ([CS]/[D518]) of 0.12 (C), $0.23(\mathrm{D}), 0.27(\mathrm{E})$, and $1.16(\mathrm{~F})$.

Fig. 8B: D 518 (A) and in the molar ratio of 0.12 (B), 0.27 (C), and 1.16 (D). (Jeon et al, J.Am. Chem. Soc., 122, 12536 (2000))

curdlan sulfate and positively charged lysine and arginine residues in the oligopeptide. When the oligopeptide of the V3 loop region (nos. 309 to 331) was mixed with curdlan sulfate, precipitates were produced. Therefore, no structural information by NMR spectroscopy afforded. These results suggest that the interaction between curdlan sulfate and V3 loop region in HIV also occurred, however, the NMR detection was limited to elucidate the interaction.

These automated fitting procedures and NMR

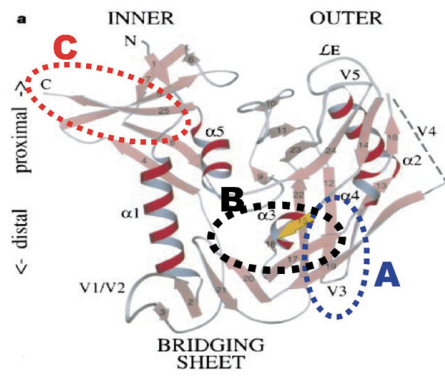

$$
\begin{aligned}
& \text { A: V3 loop region } \\
& \text { [Biotin]-297TRPNNNTRKRIRIQRGPGRA }{ }^{316} \\
& \text { B: CD4 binding domein } \\
& \text { [Biotin]-362KQSSGGDPEIVTHSFNCGG }{ }^{380} \\
& \text { C: C-terminus } \\
& \text { [Biotin]-493PLGVAPTKAKRRVVQREKR }{ }^{511}
\end{aligned}
$$

Fig. 9 Structure of gp120 and oligopeptides from the three regions. Oligopeptides from the three region of HIV gp120 were synthesized by a peptide synthesizer and the interaction with curdlan sulfate was measured by SPR. (Hansen et al., Proteins, 25, 1 (1996); Kwong et al., Nature, 393, 648 (1998); Crublet et al., J. Biol. Chem., 283, 15193 (2008)) research indicate that the anti-HIV mechanism of sulfated polysaccharides involves the electrostatic interaction between sulfated polysaccharides and HIV surface glycoprotein gp120. Thus, we used SPR and DLS to further analyze the mechanism. Three oligopeptides from HIV gp120 regions (Fig. 9) were synthesized and the interaction with curdlan and dextran sulfates was investigated [39]. The three oligopeptides were synthesized according to the reference of HIV gp 120 [ 40 - 42 ], ${ }^{297}$ TRPNNNTRKRIRIQRGPGRA ${ }^{316}$ with several lysine $(\mathrm{K})$ and arginine $(\mathrm{R})$ residues in the V3 loop region, ${ }^{493} \mathrm{PLGVAPT} \underline{\mathrm{K}} \underline{\mathrm{KRRVVQR}} \underline{\underline{\mathrm{KRR}}}{ }^{511}$ with several lysine and arginine residues in the $\mathrm{C}$-terminus region, and ${ }^{362}$ KQSSGGDPEIVTHSFNCGG ${ }^{380}$ with few basic amino acids in the CD4 binding domain. Curdlan and dextran sulfates were found to exhibit strong interactions against the two oligopeptides from the V3 and C-terminus regions, $\left(k_{a}=5.48 \times 10^{4}-2.96 \times 10^{6} 1 / \mathrm{Ms}\right.$ and $k_{d}=1.74 \times 10^{-4}-6.24 \times 10^{-3} 1 / \mathrm{s}$, res). No interaction was observed against the oligopeptide from the CD4 binding domain, probably due to the small number of positively charged amino acids. The interaction of curdlan and dextran sulfates with poly-L-lysine was also measured by SPR to provide apparent association-rate $\left(k_{a}\right)$ and dissociation-rate $\left(k_{d}\right)$ constants of $k_{a}=6.92 \times 10^{4}-2.17 \times 10^{6} 1 / \mathrm{Ms}$ and $k_{d}=4.29 \times 10^{-5}-2.22 \times$ $10^{-4} 1 / \mathrm{s}$, respectively. The particle size and zeta potential by DLS also indicated the interaction 
between curdlan and dextran sulfates with poly-Llysine. Therefore, the anti-HIV activity of sulfated polysaccharides was revealed to be induced by electrostatic interactions at the V3 loop domain from the C-terminus of HIV gp120. Longer oligosaccharides from the V3 loop and C-terminus will be synthesized, and the interaction of curdlan and dextran sulfates is determined to directly evaluate the electrostatic interaction. The SPR and DLS measurements are a superior method to evaluate the interaction between two compounds.

\section{Sulfated alkyl poly- and oligosaccharides with anti-HIV activity}

\subsection{Sulfated alkyl oligosaccharides}

The stepwise synthesis of oligosaccharides from monosaccharides requires a lot of time, labor, and cost. Therefore, in general, oligosaccharides are obtained by hydrolysis of polysaccharides. Since lower molecular weight oligosaccharides are expected to have lower cytotoxicity than polysaccharides with high molecular weights, the anti-HIV activity of sulfated oligosaccharides was examined. However, the anti-HIV activity of sulfated oligosaccharides was low due to their low molecular weights. Thus, a long-chain alkyl group was introduced at the reducing end of oligosaccharides and the anti-HIV activity was measured. Sulfated alkyl oligosaccharides have both hydrophilic sulfate and hydrophobic long-chain alkyl groups and the structure of the obtained sulfated alkyl oligosaccharides is similar structure to that of surface active agents (surfactants), which have been used to destroy lipid bilayers of cells. After introduction of the long-chain alkyl group at the reducing end of oligosaccharides, anti-HIV activity of sulfated alkyl oligosaccharides was found to remarkably increase [43-45].

Laminari- and malto-oligosaccharides composed of glucopyranosidic units from tetraose to nonaose were obtained by acetolysis of curdlan and starch with $(1 \rightarrow 3)-\beta$-D- and $(1 \rightarrow 4)-\alpha$-D-glucopyranosidic structures, respectively, followed by column chromatographic purification. Scheme 5 exhibits the synthetic route for sulfated alkyl laminarioligosaccharides. Acetolysis of curdlan was performed with a mixture of acetic anhydrate, acetic acid, and concentrated $\mathrm{H}_{2} \mathrm{SO}_{4}$ in a proportion of 4:4:1 (v/v) for $30 \mathrm{~h}$ at $35{ }^{\circ} \mathrm{C}$ to give acetylated laminarioligosaccharides in $80 \%$ yield. After purification,

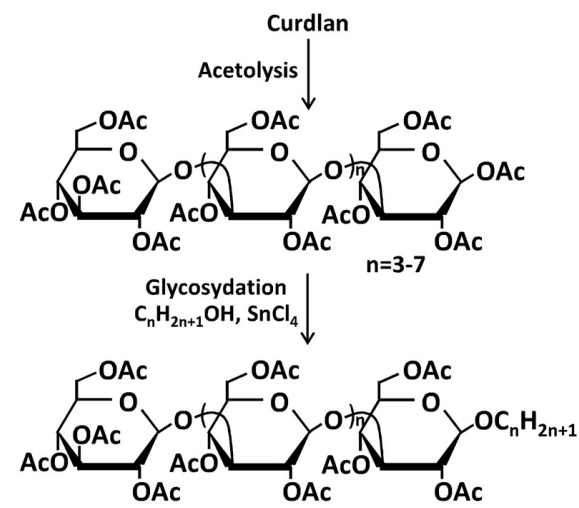

1) Deacetylation 2) Sulfation

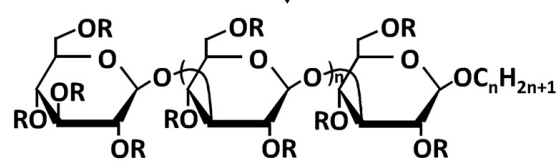

Scheme 5 Synthesis of sulfated laminari oligosaccharides. Acetolysis of curdlan followed by glycosylation with long-chain aliphatic alcohol and then sulfation after deacetylation gave sulfated alkyl oligosaccharides.

glycosylation of acetylated laminaripentaoside by $\mathrm{n}$ dodecyl alcohol in the presence of $\mathrm{SnCl}_{4}$ as a catalyst gave n-dodecyl laminaripentaoside in 53\% yield. Deacetylation with sodium in $\mathrm{MeOH}$ and sulfation with PSA gave sulfated n-dodecyl laminaripentaoside, which was purified by reprecipitation with acetone. Sulfated alkyl malto-oligosaccharides were prepared by the same procedures.

Table 1 presents the results of the anti-HIV activity of sulfated alkyl oligosaccharides. Sulfated oligosaccharides without the long-chain alkyl group exhibited low anti-HIV activity. When the long-chain alkyl group was introduced at the reducing end of oligosaccharides, the sulfated alkyl oligosaccharides exhibited potent anti-HIV activity in concentrations below $1 \mu \mathrm{g} / \mathrm{mL}$, which was as high as that of high molecular weight curdlan sulfate. The potent anti-HIV activity of sulfated alkyl oligosaccharides might be ascribed to the formation of hydrophilic and hydrophobic structures like surfactants, since sulfated alkyl oligosaccharides are easily oriented and aggregated [46]. Since the surfactants polyethylene glycol and sodium dodecyl sulfate are used for the destruction of lipid bilayers of bacteria by the hydrophobic long-chain alkyl group, the structure of sulfated alkyl oligosaccharides is similar to that of surfactants. The high anti-HIV activity of sulfated alkyl oligosaccharides is due to the amphiphilic structure bearing hydrophilic sulfate groups and the 
Table 1 Anti-HIV activity of sulfated laminara- and malto-oligosaccharides ${ }^{\text {a) }}$

\begin{tabular}{|c|c|c|c|c|c|c|}
\hline \multicolumn{4}{|c|}{ Sulfated alkyl oligosaccharides } & \multicolumn{3}{|c|}{ Anti-HIV activity $^{\mathrm{b})}$} \\
\hline \multirow[t]{2}{*}{ Sample $^{c)}$} & \multirow{2}{*}{$\begin{array}{l}\text { No. of } \\
\text { glucose }\end{array}$} & \multirow{2}{*}{\multicolumn{2}{|c|}{$\begin{array}{l}\text { C no. of } \mathrm{DS}^{\mathrm{d})} \\
\text { alkyl chain }\end{array}$}} & $\mathrm{EC}_{50}$ & $\mathrm{CC}_{50}$ & $\mathrm{AA}^{\mathrm{e})}$ \\
\hline & & & & \multicolumn{2}{|c|}{$\mu \mathrm{g} / \mathrm{mL}$} & unit/mg \\
\hline L5C12S & 5 & 12 & 3.0 & 0.10 & $>1000$ & 0 \\
\hline L7C12S & 7 & 12 & n.d. & 0.14 & $>1000$ & 0 \\
\hline L5C18S & 5 & 18 & 3.4 & 0.63 & 220 & 0 \\
\hline L7C18S & 7 & 18 & 2.8 & 0.20 & 180 & 2 \\
\hline $\mathrm{CS}^{\mathrm{f})}$ & & 0 & 1.6 & 0.18 & $>1000$ & 10 \\
\hline M5C12S & 5 & 12 & 3.4 & 0.53 & $>1000$ & 0 \\
\hline $\mathrm{M} 7 \mathrm{C} 12 \mathrm{~S}$ & 7 & 12 & 3.1 & 0.19 & $>1000$ & 3 \\
\hline M5C18S & 7 & 18 & 4.0 & 0.43 & 410 & 0 \\
\hline M7C18S & 7 & 18 & 3.3 & 0.37 & 380 & 2 \\
\hline $\mathrm{CS}^{\mathrm{f})}$ & & 0 & 1.6 & 0.4 & $>1000$ & 10 \\
\hline
\end{tabular}

a) Original data are in references [43] and [44].

b) Anti-HIV activity was evaluated by $\mathrm{EC}_{50}$ and $\mathrm{CC}_{50}$ that defied as $50 \%$ effective and cytotoxic concentrations, respectively.

c) L5C12S means sulfated dodecyl laminara-pentoglycoside, for example.

d) DS means degree of sulfation that designated the number of sulfate groups in a glucose unit.

e) Anticoagulant activity measured according to a modification of the United States Pharmacopoeia using bovine plasma and dextran sulfate (21.0 unit/mg) was used as a reference [11].

f) Curdlan sulfate with $\overline{\mathrm{M}}_{\mathrm{n}}=7.9 \times 10^{4}$ was used as a reference for anti-HIV activity.

hydrophobic long-chain alkyl group at the reducing end of oligosaccharides. The cytotoxicity of sulfate dodecyl oligosaccharides was low in concentrations as low as $\mathrm{CC}_{50}=1000 \mu \mathrm{g} / \mathrm{mL}$, however, sulfated octadecyl oligosaccharides exhibited relatively high cytotoxicity, $\mathrm{CC}_{50}=180-400 \mu \mathrm{g} / \mathrm{mL}$. The reason why the cytotoxicity increased is presented in section 3-6.

In addition, sulfated octadecyl ribofuranans bearing low molecular weights were prepared by ring-opening polymerization of a benzylated ribose monomer, 1, 4-anhydro-2, 3-di-O-benzyl- $\alpha$-Dribopyranose, and then debenzylation and glycosylation followed by sulfation [47]. Since anti-HIV activity is depended on the molecular weights, sulfated ribofuranans and ribopyranans bearing high molecular weights had potent anti-HIV activity [48, 49]. However, the activity decreased with decreasing molecular weights. After the long-chain alkyl group

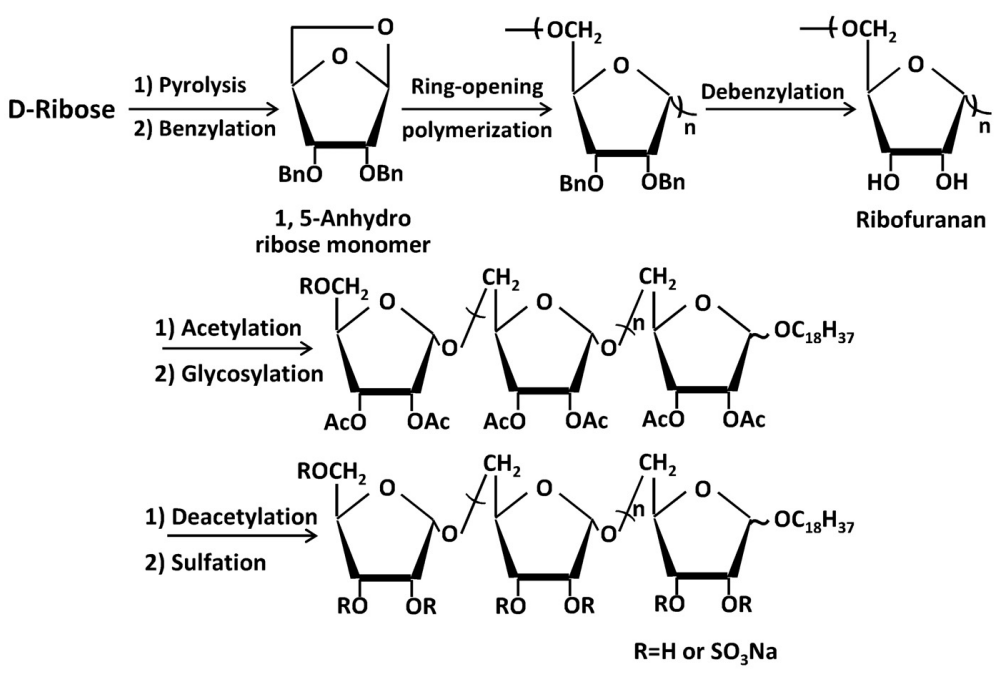

Scheme 6 Synthesis of sulfated octadecyl ribofuranan with medium-range molecular weights. Sulfated octadecyl ribofuranan was prepared by ring-opening polymerization of anhydro ribose monomer and glycosylation followed by sulfation. 
was introduced at the reducing end of the low molecular weight ribofuranans, the anti-HIV activity improved. Scheme 6 exhibits the synthesis of sulfated octadecyl ribofuranan. It was found that sulfated octadecyl ribofuranan bearing a low molecular weight of $\overline{\mathrm{M}}_{\mathrm{n}}=6 \times 10^{3}$ had potent anti-HIV activity $\left(\mathrm{EC}_{50}=\right.$ $0.6 \mu \mathrm{g} / \mathrm{mL}$ ), which was almost the same as that of referenced ribofuranan sulfate with $\overline{\mathrm{M}}_{\mathrm{n}}=9 \times 10^{3}$ and curdlan sulfate with $\overline{\mathrm{M}}_{\mathrm{n}}=79 \times 10^{3}, \mathrm{EC}_{100}=3.3 \mu \mathrm{g} / \mathrm{mL}$, and $\mathrm{EC}_{50}=0.43 \mu \mathrm{g} / \mathrm{mL}$, respectively. Furthermore, sulfated octadecyl ribofuranan bearing low molecular weight of $\overline{\mathrm{M}}_{\mathrm{n}}=3 \times 10^{3}$ was found to exhibit relatively high anti-HIV activity at a concentration of $\mathrm{EC}_{50}=$ $2.5 \mu \mathrm{g} / \mathrm{mL}$. The enhancement of the anti-HIV activity of the low molecular weight sulfated octadecyl ribofuranans was due to the introduction of octadecyl group. The cytotoxicity of sulfated octadecyl ribofuranans was low, $\mathrm{CC}_{50}>1000 \mu \mathrm{g} / \mathrm{mL}$. It is necessary to balance the length of hydrophobic longchain alkyl groups and hydrophilic oligosaccharide moieties for high anti-HIV activity and low cytotoxicity [43-45].

In the case of the sulfated octadecyl ribofuranan compared with that of sulfated octadecyl oligosaccharides as described above, the molecular weight of ribofuranan moiety was relatively higher than that of laminari- and malto-oligosaccharides, so sulfated octadecyl ribofuranans might exhibit low cytotoxicity. The blood anticoagulant activity of sulfated octadecyl ribofuranan was low, AA=417 unit/mg, compared with that of sulfated ribofuranan with high molecular weight of $\overline{\mathrm{M}}_{\mathrm{n}}=9 \times 10^{3}$, $\mathrm{AA}=56 \mathrm{unit} / \mathrm{mg}$. The low blood anticoagulant activity was caused by the low molecular weight of the sulfated octadecyl ribofuranans. The long-chain alkyl group was independent of the blood anticoagulant activity because the anticoagulant activity was induced by the electrostatic interaction between negatively charged sulfated polysaccharides and a positively charged protease inhibitor, antithrombin III [17].

\subsection{Role of long-chain alkyl group in sulfated alkyl oligosaccharides}

The role of the long-chain alkyl group in sulfated alkyl oligosaccharides with potent anti-HIV activity might be similar to the results for sulfated alkyl polysaccharides. The role of the long-chain alkyl group in sulfated alkyl oligosaccharides was also investigated by the combination of SPR and DLS measurements [50]. Sulfated maltoheptaoside with a long-chain alkyl group was newly synthesized by using click reaction of 1-dodecine and 1-azido acetylated maltoheptaoside in good yield as exhibited in Scheme 7. The long-chain alkyl group was attached at the reducing end of maltoheptaose through the triazole ring. Both alkyl oligosaccharides, 1-(decadecyl1, 2, 3-triazoyl)-1-deoxy-maltoheptaoside (dodecyl maltoheptaoside) and sulfated 1-(decadecyl-1, 2, 3triazoyl)-1-deoxy-maltoheptaoside (sulfated dodecyl maltoheptaoside) gave the SPR signals, respectively. However, maltoheptaose and sulfated maltoheptaose without long-chain alkyl group afforded no SPR signals. The particle size of the maltoheptaosides bearing long-chain alkyl group increased in the presence of liposome, however, for the maltoheptaosides without long-chain alkyl group, the particle size was not changed. The $\zeta$ potential of sulfated maltoheptaosides exhibited negative values and maltoheptaosides without sulfation gave approximately zero $\mathrm{mV}$.

Fig. 10 shows the proposed interaction between sulfated dodecyl maltoheptaoside and liposome. Considering of the SPR and DLS results on sulfated octadecyl maltoheptaosides, the long-chain alkyl

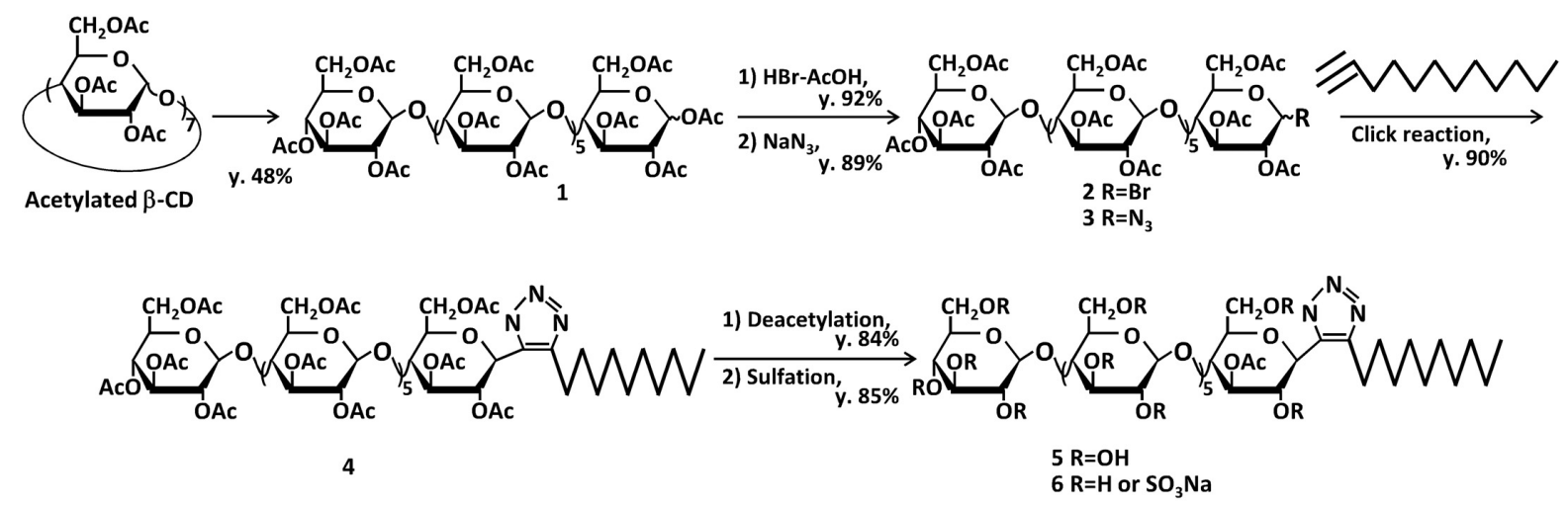

Scheme 7 Synthesis of sulfated oligosaccharides with a long-chain alkyl group at the reduced end. Click reaction is the key reaction of the synthesis. 


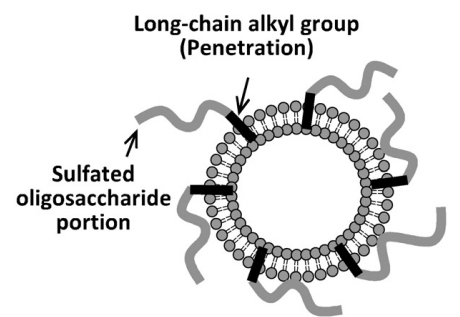

Fig. 10 Proposed model of the interaction of sulfated alkyl oligosaccharides with liposome. Longchain alkyl group was penetrated into liposome and then sulfated oligosaccharide portion having negative charges was electrostatically interacted with positively charged HIV gp120 to cover the surface of HIV.

group penetrated into the lipid bilayer of HIV and then the sulfated maltoheptaoside portion electrostatically interacted with HIV gp120 to inhibit HIV infection in vitro.

\subsection{Interaction of 3-O-octadecyl dextran with liposome}

In this section, the role of the long-chain alkyl group in sulfated polysaccharides is described. As mentioned above sections, the anti-HIV mechanism of sulfated polysaccharides is originated from the electrostatic interaction. For sulfated alkyl poly and oligosaccharides, a pioneering research on the interaction of synthetic dextran bearing long-chain alkyl group and liposome was reported by Kobayashi in 1986 (Fig. 11) [51].

This research is a highly regarded study into the role of the long-chain alkyl group in anti-HIV activity and cytotoxicity. The interaction between 3-Ooctadecyl dextran bearing a degree of substitution (DSUB) of 0.03 and liposome was analyzed by a gel chromatography using Sephadex G-50 [51]. The longchain alkyl group was found to interact with liposome to produce the complex. The dissociation was suppressed when the long-chain alkyl groups attached to dextran anchored deeply into the lipid bilayer of liposome. The octadecyl group exerted a stronger anchoring effect against liposome than the shorter dodecyl group. In addition, no dextran-coated liposomes were isolated when 3-O-octadecyl dextran at more than $\mathrm{DSUB}=0.07$ was used. The reasons for decreasing interaction were considered as follows: (1) Although the octadecyl groups exhibited potent anchoring effect, too many octadecyl groups (DS> 0.07) disordered the structure of liposomes, which became unstable. (2) The mobility of the dextran molecules was restricted due to the anchoring of octadecyl groups into the liposome revealed by the fluorescence polarization measurement of 3-Ooctadecyl dextran. These results were suggestive for the potent anti-HIV and cytotoxicity of sulfated alkyl poly-and oligosaccharides as described below.

\subsection{Interaction of sulfated 3-O-octadecyl dextran and poly-L-lysine}

Recently, water-soluble sulfated 3-O-octadecyl dextrans bearing the DSUB of $2.8-4.7 \mathrm{~mol} \%$ and lower molecular weights of $\overline{\mathrm{M}}_{\mathrm{n}}=2.5 \times 10^{3}-5.1 \times 10^{3}$ were synthesized and the anti-HIV activity were measured by comparison with that of standard dextran and curdlan sulfate $\left(\mathrm{EC}_{50}=0.05 \mu \mathrm{g} / \mathrm{mL}\right.$ and $\left.0.18 \mu \mathrm{g} / \mathrm{mL}\right)$. These sulfated 3-O-octadecyl dextrans were found to have potent anti-HIV activity at $\mathrm{EC}_{50}=0.05 \mu \mathrm{g} / \mathrm{mL}-$ $1.25 \mu \mathrm{g} / \mathrm{mL}$ [52]. The interaction with poly-L-lysine was analyzed by SPR, indicating that sulfated 3-Ooctadecyl dextrans with $\overline{\mathrm{M}}_{\mathrm{n}}=5.1 \times 10^{3}$ and $\overline{\mathrm{M}}_{\mathrm{n}}=2.5 \times 10^{3}$ had high association- and low dissociation-rate constants, $k_{d}=3.1 \times 10^{-4}$ and $k_{d}=1.0 \times 10^{-3}$, respectively. The particle size measured by DLS increased after adding poly-L-lysine, suggesting that sulfated 3-Ooctadecyl dextrans were electrostatically interacted with poly-L-lysine to expand the particle size. For the

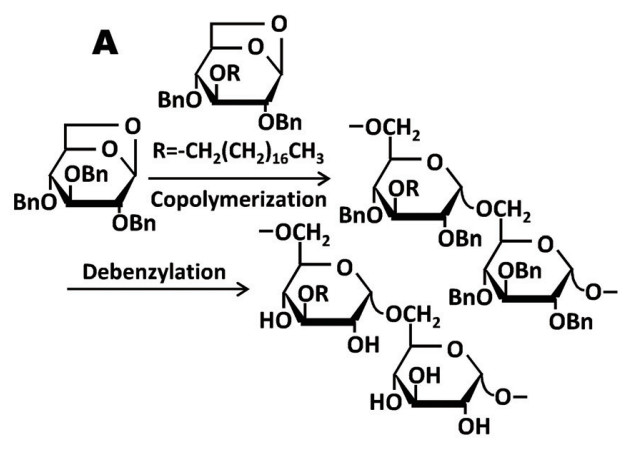

\section{B}

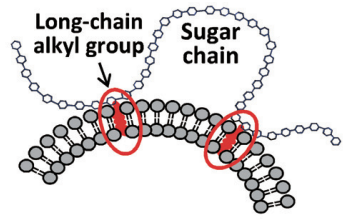

Fig. 11 Proposed interaction of long alkyl group in polysaccharide with liposome. (A) Synthesis of 3-O-octadecyl dextran by ring-opening copolymerization and (B) Interaction of long-chain alkyl group with liposome. Long-chain alkyl group was penetrated into liposome. (Kobayashi et al., Macromolecules, 19, 529 (1986)) 
interaction with poly-L-lysine, the octadecyl group could be independent of the binding of sulfated 3-Ooctadecyl dextrans to poly-L-lysine because of having no charges. However, since the anti-HIV activity of sulfated 3-O-octadecyl dextrans bearing low molecular weight increased, the hydrophobic octadecyl group and hydrophilic dextran sulfate moiety were assumed to be induced synergistic effect against HIV. In the next section, the role of the longchain alkyl group against HIV is presented.

\subsection{Interaction of sulfated 3-O-octadecyl dextran and liposome}

As described in section 3-2, the potent anti-HIV activity of sulfated alkyl poly- and oligosaccharides is assumed to involve the penetration of the long-chain alkyl group into the lipid bilayer of HIV and then the sulfated oligosaccharide moiety should electrostatically interact with HIV surface glycoprotein gp120 to inhibit the infection of HIV into cells. Thus, the interaction of sulfated 3-O-octadecyl dextrans with liposomes was directly investigated by SPR and DLS analyses [53]. Two liposomes bearing diameters of $58 \pm 20 \mathrm{~nm}$ and $107 \pm 28 \mathrm{~nm}$ as models of HIV were used. SPR measurements of sulfated 3-Ooctadecyl dextran bearing $2.8 \mathrm{~mol} \%$ of octadecyl group with liposome (diameter $=58 \pm 20.0 \mathrm{~nm}$ and $\zeta=$ $0 \mathrm{mV}$ ) resulted in an apparent association- and dissociation-rate constants of $k_{a}=6 \times 10^{5} 1 / \mathrm{M}$ and $k_{d}=4 \times$ $10^{-4} \mathrm{l} / \mathrm{s}$, respectively. The particle size of sulfated 3-Ooctadecyl dextran $(67 \pm 14 \mathrm{~nm})$ measured by DLS increased to $104 \pm 25 \mathrm{~nm}$, whereas the $\zeta$ potential $(-29 \mathrm{mV})$ was unchanged $(-33 \mathrm{mV})$. These results suggest that the long octadecyl group penetrated into the liposome lipid bilayer and sulfated glucopyranan covered the liposome. The $107 \mathrm{~nm}$ liposome exhibited similar results.
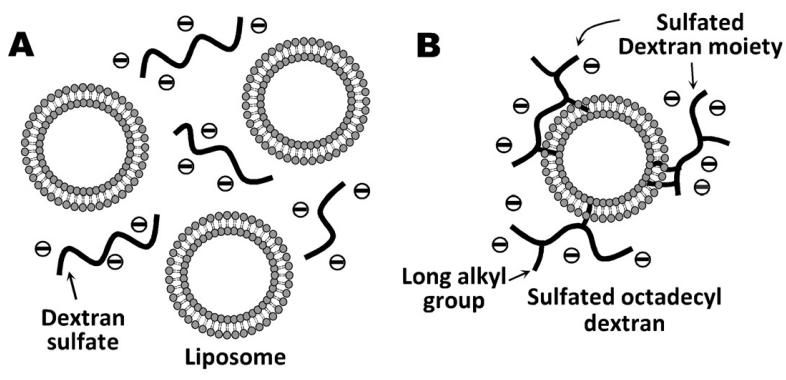

Fig. 12 Illustration of the interaction between (A) liposome and dextran sulfate and (B) liposome and 3-O-octadecyl dextran sulfate. The octadecyl groups penetrated into the lipid bilayer of liposomes to increase particle size and the $\zeta$ potential changed.
Fig. 12 shows the proposed illustration of the interaction of (A) liposome and dextran sulfate and (B) liposome and sulfated 3-O-octadecyl dextran. For dextran sulfate in Fig. 12A, the particle size of the liposomes did not change and the $\zeta$ potential decreased, suggesting that dextran sulfate was present in the system without any interaction. For sulfated 3-O-octadecyl dextran in Fig. 12B, the long octadecyl group penetrates into the liposome, and the fixed sulfated dextran moiety covers the surface of the liposome to expand the particle sizes, and the $\zeta$ potential became similar to that of sulfated 3-Ooctadecyl dextran alone. Taking into account the results, the long-chain alkyl group works effectively by penetrating or anchoring into the lipid bilayer of HIV to improve anti-HIV activity, and subsequent electrostatic interaction between negatively charged sulfated polysaccharide moieties and positively charged HIV gp120 portions occurred and contributes to the anti-HIV activity. This consideration aligns with the previous research as described in this section [34].

\subsection{Anti-HIV effect of sulfated alkyl poly and oligosaccharides}

As mentioned in the sections 3.1-3.5, sulfated oligosaccharides had low anti-HIV activity [43-45] because the activity was depended on the molecular weights and degrees of sulfation [23, 47]. However, we found that the activity increased with introducing a long-chain alkyl group into sulfated oligosaccharides at the reducing end and the mechanism was elucidated by SPR and DLS measurements.

For sulfated polysaccharides bearing low molecular weights, introduction of a small amount of long-chain alkyl group was effective for the potent anti-HIV activity as high as that of sulfated polysaccharides bearing high molecular weights. As described in the sections 3.4 and 3.5, from the measurements of SPR and DLS using liposome, the long-chain alkyl group was anchored into the lipid bilayer of liposome, suggesting that anti-HIV mechanism of alkyl polysaccharides, for example, sulfated 3-O-octadecyl dextran bearing $2.8 \mathrm{~mol} \%$ of 3$O$-octadecyl glucopyranosidic unit is attributed to the synergistic effect of the penetration of long-chain alkyl group and then electrostatic interaction between sulfated groups and gp120 of HIV surface glycoprotein.

Therefore, the structural difference between sulfated alkyl poly and oligosaccharides on anti-HIV 
activity was as follows: (1) Position of alkyl group. The long-chain alkyl group was introduced into the reducing end of oligosaccharides and 3-O-position of sugar unit of polysaccharides, respectively, due to their synthetic problems. (2) Regarding anti-HIV activity. Although sulfated polysaccharides without long-chain alkyl group had potent anti-HIV activity, sulfated oligosaccharides bearing low molecular weights had low activity. After the long-chain alkyl group was introduced, the activity increased due to the penetration into lipid bilayer of HIV. The cytotoxicity also increased with increasing the length of the alkyl chain as described in the next section. Thus, we found that the balance between hydrophilic sulfated oligosaccharide moiety and hydrophobic long-chain alkyl group was important for high activity and low cytotoxicity.

\subsection{Cytotoxicity of sulfated alkyl poly and oligosaccharides}

As described in the section 3.3, the longer octadecyl group exhibited more anchoring into the liposome lipid bilayer than the relatively shorter dodecyl group, however, the liposome became unstable for the large number of penetrated octadecyl groups in 3-O-octadecyl dextran [51]. Furthermore, considering the results regarding the interaction between sulfated 3-O-octadecyl dextran and liposome [53], the cytotoxicity of sulfated octadecyl oligosaccharides may be induced by the octadecyl groups with stronger interactions into cells than that of dodecyl groups.

For sulfated alkyl oligosaccharides, cytotoxicity in MT-4 cell increased when the length of alkyl groups increased [43-45]. The cytotoxicity of sulfate dodecyl oligosaccharides was low in concentrations as low as $\mathrm{CC}_{50}=1000 \mu \mathrm{g} / \mathrm{mL}$, however, cytotoxicity increased when the length of long-chain alkyl groups increased. Sulfated octadecyl oligosaccharides exhibited relatively high cytotoxicity, $\quad \mathrm{CC}_{50}=180$ $400 \mu \mathrm{g} / \mathrm{mL}$. The hydrophobic and hydrophilic balance of the long-chain alkyl group and sulfated oligosaccharide moiety play a significant role in the high anti-HIV activity and low cytotoxicity.

Newly synthesized sulfated octadecyl maltoheptaoside 6 in scheme 7 also exhibited the similar cytotoxic results [50]. It was concluded that the liposome became unstable by the long-chain alkyl groups bearing carbon number more than $\mathrm{C} 12$, namely, the cytotoxicity of sulfated alkyl oligosaccharides in MT-4 cell increased. We have continuously synthesized several sulfated alkyl maltoheptaosides bearing different lengths (C6-C18) of the long-chain alkyl group at the reducing end and investigated the relationship between sulfated alkyl oligosaccharides and cytotoxicity by means of SPR and DLS measurements.

\section{Conclusion}

In conclusion, sulfated polysaccharides have potent anti-HIV activity originating from the interaction of negatively charged sulfate groups in sulfated polysaccharides and positively charged amino acids in HIV gp120. This mechanism was evaluated by using the Chem-X software program, gel filtration method, NMR, SPR, and DLS measurements. In addition, the long-chain alkyl group in sulfated alkyl poly- and oligosaccharides was found to enhance the anti-HIV activity. From the results of gel chromatography, fluorescence experiments, and SPR and DLS measurements, the role of the long-chain alkyl group penetrated in the lipid bilayer of HIV and enhanced the anti-HIV activity by the synergistic effect with sulfated poly- and oligosaccharide moieties. As a result, the infectivity of HIV decreased in vitro. The cytotoxicity of sulfated alkyl oligosaccharides increases with increasing the length of long-chain alkyl group probably because of the too strong anchoring effect of the long-chain alkyl groups. Therefore, hydrophilic and hydrophobic balances in sulfated alkyl oligosaccharides are important for high anti-HIV activity and low cytotoxicity. Further studies on anti-HIV activity and cytotoxicity of sulfated alkyl poly- and oligosaccharides are in progress.

This review mainly described the results regarding the anti-HIV activity and mechanism of sulfated poly and oligosaccharides. These results may lead to more extensive investigations into the adaptability of other envelope viruses. In future studies, sulfated alkyl poly and oligosaccharides with potent antiviral activities and low cytotoxicity will be developed, and then apply these sulfated poly- and oligosaccharides to biomaterials to create virusremoving functionality that works effectively outside of the human body, for example, masks, fibers, filters, resins, and so on. 


\section{Acknowledgments}

First of all, the author is sincerely grateful to Professor Emeritus Toshiyuki Uryu of University of Tokyo for valuable discussions, his continuing interest, and encouragement. The author is indebted to Professors Daisuke Asai (who moved to Showa Pharmaceutical University), Hiromu Takemura, Taisei Kanamoto (who moved to Showa Pharmaceutical University), and Hideki Nakashima (Professor Emeritus) of Department of Microbiology, St. Marianna University School of Medicine for the antiviral tests, many useful suggestions, discussions, and improvement. Ms. Shigemi Terakubo of the microbiology laboratory was carried out the antiviral assay. The author particularly acknowledges. The author also appreciates many students as colleagues listed in the references, whose forces are the motivation of the works. Lastly, the author wishes to thank support for the above works by grants from Grant-in-Aids for Scientific Research from Japan Society for the Promotion of Science, and Iketani Science and Technology Foundation.

\section{References}

1. S. Dumitaiu, ed., Polysaccharides: Structural diversity and functional versatility 2nd Ed. Marcel Dekker, New York, (2005).

2. Z. J. Witczak, K. A. Nieforth, ed., Carbohydrates in drug design. Marcel Dekker, New York, (1997).

3. C. Schuerch, Adv. Polym. Sci. 39, 157 (1981).

4. T. Uryu, Polysaccharides. In Models of biopolymers by ring-opening polymerization.

S. Penczek, ed., CRC Press, Boca Raton, FL., 133 (1990).

5. T. Yoshida, Prog. Polym. Sci., 263, 79 (2001).

6. E. R. Ruckel, C. Schuerch, J. Org. Chem., 31, 2233 (1966).

7. T. Uryu, K. Kitano, K. Ito, J. Jamanouchi, K. Matsuzaki, Macromolecules, 14, 1 (1981).

8. T. Uryu, J. Jamanouchi, T. Kato, S. Higuchi, K. Matsuzaki, J. Am. Chem. Soc., 105, 6855 (1983).

9. T. Uryu, J. Jamanouchi, S. Hayashi, H. Tamaki, K. Matsuzaki, Macromolecules, 16, 320 (1983).

10. T. Uryu, H. Libert, J. Zachoval, C. Schuerch, Macromolecules, 3, 345 (1970).

11. T. Yoshida, M. Kida, T. Uryu, Polymer J., 19, 923 (1987).

12. K. Hattori, T. Yoshida, Macromolecules, 42, 6044
(2009).

13. D. Yoshida, T. Yoshida, J. Polym. Sci. Part A: Polym. Chem., 47, 1013 (2009).

14. K. Nagasawa, H. Yoshidome, Chem. Pharm. Bull., 17, 1316 (1969).

15. D. A. Lane, U. Lindahl, Heparin. Chemical and biological properties clinical application. CRC Press, Boca Raton, FL., (1989).

16. D. A. Lane, I. Bjork, U. Lindahl, Heparin and related polysaccharides: Advances in Experimental Medicine and Biology, vol. 313. Plenum press, New York, (1992).

17. U. Lindahl, G. Backstrom, L. Thunberg, J. Biol. Chem., 258, 9826 (1983).

18. J. A. Marcam, R. D. Rosenberg, Regulation of the blood coagulation mechanism by anticoagulantly active heparin sulfate proteoglycans. In Biology of carbohydrates vol. 3. V. Cinsberg, P. W. Robbins, ed., JAI Press Ltd. London (1991).

19. K. Hatanaka, T. Yoshida, S. Miyahara, T. Sato, F. Ono, T. Uryu, H. Kuzuhara, J. Med. Chem., 30, 810 (1987).

20. T. Yoshida, H. Nakashima, N. Yamamoto, T. Uryu, Polymer J., 25, 1069 (1993).

21. H. Nakashima, O. Yoshida, T. Tochikura, T. Yoshida, T. Mimura, Y. Kido, Y. Motoki, Y. Kaneko, T. Uryu, N. Yamamoto, Jpn. J. Cancer Res. Gann, 78, 1164 (1987).

22. T. Harada, Trends Glycosci. Glycotech., 4, 309 (1992).

23. T. Yoshida, K. Hatanaka, T. Uryu, Y. Kaneko, E. Suzuki, H. Miyano, T. Mimura, O. Yoshida, N. Yamamoto, Macromolecules, 23, 3717 (1990).

24. O. Yoshida, H. Nakashima, T. Yoshida, Y. Kaneko, I. Yamamoto, K. Matsuzaki, T. Uryu, N. Yamamoto, Biochem. Pharm., 37, 2887 (1988).

25. M. Gordon, M. Guralnik, Y. Kaneko, T. Mimura, M. Baker, T. Lang, J. Med., 25, 163 (1994).

26. M. Gordon, S. Deeks, D. D. Marzo, J. Goodgame, T. Lang,, M. Guralnik, W. Lang., T. Mimura, D. Pearce, Y. Kaneko. J. Med., 28, 108 (1997).

27. S. Han, Y. Kanematsu, K. Hattori, H. Nakashima, T. Yoshida, J. Polym. Sci. Part A: Polym. Chem., 47, 913 (2009).

28. W. Song, Y. Li, T. Kanamoto, D. Asai, H. Takemura, H. Nakashima, K. Miyazaki, T. Yoshida, Carbohydr. Res., 495, 108084 (2020).

29. K. Ichiyama, S. Bhargavi, G. Reddy, F. Z. Li, X. C. Wei, T. Muschin, H. Lars, Y. Suzuki, H. Nanjundappa, Y. Yoshinak, A. Ryo, N. Nomura, E. Eng, O. S. G. Vasudevan, T. Yoshida, N. 
Yamamoto, PLOS Neglected Tropical Diseases, 7, e 2188, 1 (2013).

30. M. Tegshi, Budragchaa, T. Kanamoto, H. Nakashima, K. Ichiyama, N. Yamamoto, S. Han, T. Yoshida, Int. J. Biol. Macromol., 89, 415 (2016).

31. M. Tegshi, S. Han, T. Kanamoto, H. Nakashima, T. Yoshida, J. Polym. Sci. Part A: Polym. Chem., 49, 3241 (2011).

32. http:/www.fludb.org/.

33. K. L. Hartshorn, 1, M. R. White, D. R. Voelker, J. Coburn, K. Zaner, E. C. Crouch, Biochem. J., 351, 449 (2000).

34. T. Uryu, N. Ikushima, K. Katsuraya, T. Shoji, N. Takahashi, T. Yoshida, K. Kanno, T. Murakami, H. Nakashima, N. Yamamoto, Biochem. Pharmacol., 43, 2385 (1992).

35. P. P. Jagodzinski, R. Wiaderkiewicz, G. Kurzawski, M. Kloczewiak, H. Nakashima, E. Hyjek, N. Yamamoto, T. Uryu, Y. Kaneko, M. R. Posner, D. Kozbor, Virology, 202, 735 (1994).

36. P. P. Jagodzinski, J. Wustner, D. Kmieciak, T. J. Wasik, A. Fertala, A. L. Sieron, M. Takahashi, T. Tsuji, T. Mimura, M. S. Fung, M. K. Gorny, M. Kloczewiak, Y. Kaneko, D. Kozbor, Virology, 225, 217 (1996).

37. K. J. Jeon, K. Katsuraya, Y. Kaneko, T. Mimura, T. Uryu, Macromolecules, 30, 1997 (1997).

38. K. J. Jeon, K. Katsuraya, T. Inazu, Y. Kaneko, T. Mimura, T. Uryu, J. Am. Chem. Soc., 122, 12536 (2000).

39. T. Battulga, O. Tumurbaatar, O. Ganzorig, T. Ishimura, T. Kanamoto, H. Nakashima, K. Miyazaki, T. Yoshida, Int. J. Biol. Macromol., 125, 909 (2019).

40. J. E. Hansen, O. Lund, J. O. Nielsen, S. Brunak, E. S. Hansen, Proteins, 25, 1 (1996).
41. P. D. Kwong, R. Wyatt, J. Robinson, R. W. Sweet, J. Sodroski, W. A. Hendrickson, Nature, 393, 648 (1998).

42. E. Crublet, J. P. Andrieu, R. R. Vives, H. LortatJacob, J. Biol. Chem., 283, 15193 (2008).

43. K. Katsuraya, N. Ikushima, N. Takahashi, T. Shoji, H. Nakashima, N. Yamamoto, T. Yoshida, T. Uryu, Carbohydr. Res., 260, 51 (1994).

44. K. Katsuraya, T. Shoji, K. Inazawa, H. Nakashima, N. Yamamoto, T. Uryu, Macromolecules, 27, 6695 (1994).

45. K. Katsuraya, T. Shibuya, K. Inazawa, H. Nakashima, N. Yamamoto, T. Uryu, Macromolecules, 28, 6697 (1995).

46. T. Uryu, K. Katsuraya, T. Yoshida, J. M. S. Pure Appl. Chem., A33, 1863 (1996).

47. Y. S. Choi, T. Yoshida, T. Mimura, Y. Kaneko, H. Nakashima, N. Yamamoto, T. Uryu, Carbohydr. Res., 282, 113 (1996).

48. T. Yoshida, Y. Katayama, S. Inoue, T. Uryu, Macromolecules, 25, 4051 (1992).

49. T. Yoshida, C. Wu, L. Song, T. Uryu, Y. Kaneko, T. Mimura, H. Nakashima, N. Yamamoto. Macromolecules, 27, 4422 (1994).

50. M. Bai, C. Bai, D. Asai, H. Takemura, K. Miyazaki, T. Yoshida, Carbohydr. Polym., 245, 116518 (2020).

51. K. Kobayashi, H. Sumitomo, H. Ichikawa, 19, 529 (1986).

52. S. Bai, D. Budragchaa, S. Han, T. Kanamoto, H. Nakashima, T. Uryu, T. Yoshida, Int. J. Polym. Sci., 317420 (2015)

53. D. Budragchaa, S. Bai, T. Kanamoto, H. Nakashima, K. Miyazaki, T. Yoshida, Carbohydr. Polym. 245, 116022 (2020). 